\title{
CYCLOSTATIONARY ANALYSIS OF POLYTIME CODED SIGNALS FOR LPI RADARS
}

\author{
Metuku Shyamsunder ${ }^{1}$, Kakarla Subbarao ${ }^{2}$ \\ ${ }^{1}$ Assistant Professor,Department of ECE, Osmania University, Telangana, India \\ ${ }^{2}$ Professor, Department of ECE, CBIT, Telanagana, India
}

\begin{abstract}
In Radars, an electromagnetic waveform will be sent, and an echo of the same signal will be received by the receiver. From this received signal, by extracting various parameters such as round trip delay, doppler frequency it is possible to find distance, speed, altitude, etc. However, nowadays as the technology increases, intruders are intercepting transmitted signal as it reaches them, and they will be extracting the characteristics and trying to modify them. So there is a need to develop a system whose signal cannot be identified by no cooperative intercept receivers. That is why LPI radars came into existence. In this paper a brief discussion on LPI radar and its modulation (Polytime code (PT1)), detection (Cyclostationary (DFSM \& FAM) techniques such as DFSM, FAM are presented and compared with respect to computational complexity.
\end{abstract}

Keywords-LPI Radar, Polytime codes, Cyclostationary DFSM, and FAM

\section{INTRODUCTION}

The radar is an abbreviation for RAdio Detection And Ranging expression. In general, the radar systems use modulated waveforms and directive antennas to transmit electromagnetic energy into a specific volume in space to search for targets. Objects (or targets) within a special search volume will reflect back to the radar a portion of this energy (radar returns or echoes). These echoes are processed by the radar receiver to extract target information such as range, velocity, angular position, and other target identifying characteristics [1].A low probability of intercept (LPI) radar is defined as radar that uses a special emitted waveform intended to prevent a non cooperative intercept receiver from intercepting and detecting its emission. The LPI radar has different modulation and detecting techniques of them we are going to discuss following. A study conducted on the implementation of Barker code and linear frequency modulation pulse compression technique has shown that the SNR and Range resolution were improved even for targets having very low RCS, but failed to prove quantitatively [2]. A group of scientists presented modeling and analysis of LPI radar signals using Barker and polyphase codes which only gives the time and frequency changes, but could not extract the required parameters such as center frequency, Bandwidth, and code rate [3]. FMCW modulated LPI signals were analyzed using Wiener Ville Distribution, the performance of which is limited for the estimation of the center frequency in the frequency agility conditions [4]. This paper focused on the Polytime codes modulated LPI signals and extraction of its parameters using efficient methods of cyclostationary signal processing. The analysis performed under different SNR conditions with different methods such as DFSM, FAM and compared quantitatively.

\section{POLYTIME CODE (T1(n))}

The Polytime codes are counterparts of polyphase codes in which phase along with time spent at each phase state will changes. There are four types of Polytime codes T1, T2, T3 and T4 out of which T1 is discussed below. The T1, T2 codes arise from stepped-RF waveform whereas the T3, T4 from linear-FM waveforms. T1(n) is an approximation to stepped-RF waveform with zero beat at its leading edge. The ' $n$ ' indicates the number of phase states used to approximate the underlying waveform. The proposed work uses only two phase states ( 0 and 180). The signal is of $16 \mu \mathrm{Sec}$ is divided into four segments each of $4 \mu \mathrm{Sec}$. Among the four segments the first segment has no signal, and the second segment has one full cycle (3600). The third segment consists of two full cycles (7200), and the fourth segment has three full cycles (10800) resulting in a total accumulated phase of 21600. The Fig.1 shows the unwrapped accumulated phase and quantized wrapped phase of a stepped-RF signal.

The above wrapped phase quantized to 00 and 1800 can be directly generated by using the equation.(1)

$$
\varphi(t)=\operatorname{MOD}\left[\frac{2 \pi}{n} \operatorname{INT}(k t-j T) \frac{j n}{T}, 2 \pi\right]
$$

$\mathrm{n}=$ number of phase states

$\mathrm{k}=$ number of segments

$\mathrm{T}=$ Total code duration

$\mathrm{j}=$ segment number 

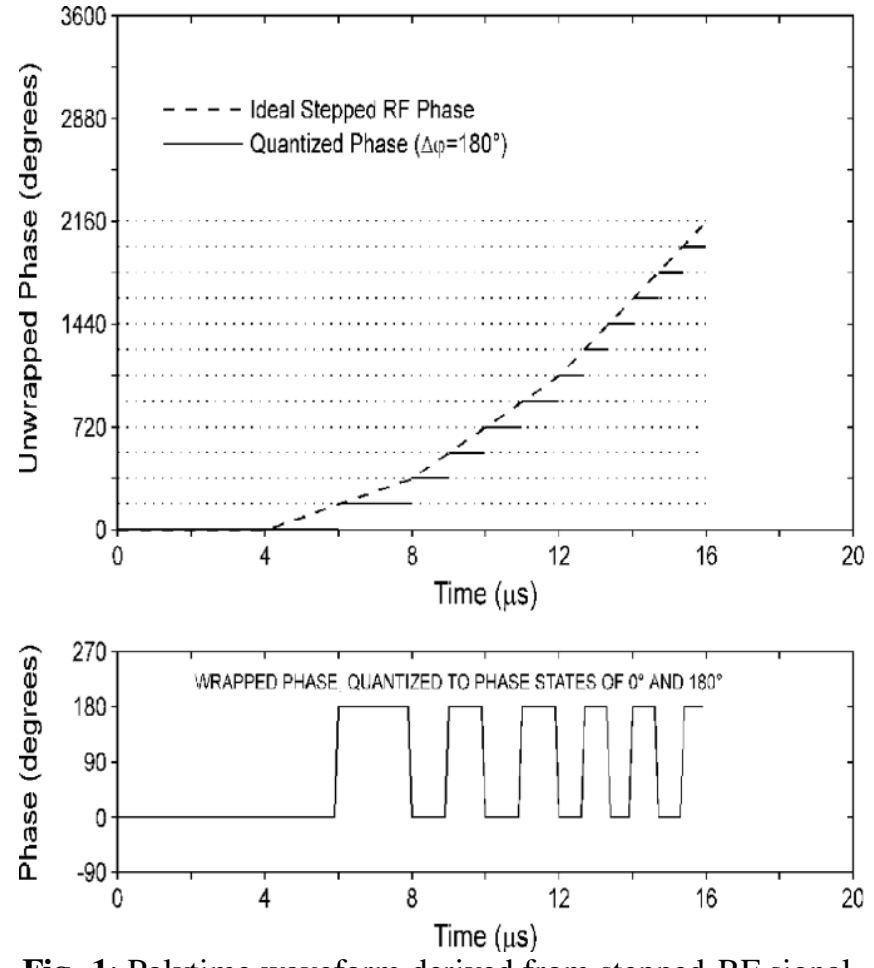

Fig -1: Polytime waveform derived from stepped-RF signal

\section{CYCLO STATIONARY SIGNAL}

\section{PROCESSING}

In general all periodic signals are deterministic in nature. By applying directly Fourier transform, we can extract parameters from the signal. Coming to modulated signals they are not truly periodic. By performing a nonlinear transformation, we can convert them into periodic. Previously a quadratic transform is used in which the signal is squared followed by applying FFT to get the spectral lines. However, squaring is not recommended in some cases such as PCM in which only amplitude of \pm 1 that on squaring hides all the spectral lines giving a DC 1 . So a delay must be introduced. Let $\mathrm{x}(\mathrm{t})$ be a Polytime coded signal which is not periodic then we convert this signal into a periodic signal $\mathrm{y}(\mathrm{t})$ as given in the equation (2)

$$
y(t)=x(t) x(t-\tau)
$$

In cyclostationary there are two methods time smoothing FFT accumulation method and direct frequency smoothing method. The cyclic auto correlation function and spectral correlation density function are the two important parameters in cyclostationary.

The cyclic auto correlation function can be given in equation (3)

$$
R_{x}^{\alpha}(\tau)=\lim _{T \rightarrow \infty} \frac{1}{T} \int_{-T / 2}^{T / 2} x\left(t+\frac{\tau}{2}\right) x^{*}\left(t-\frac{\tau}{2}\right) e^{-j 2 \pi \alpha t} d t
$$

The spectral correlation density is given in equation (4)

$$
\begin{aligned}
S_{x}^{\alpha}(f)=\int_{-\infty}^{\infty} R_{x}^{\alpha}(\tau) e^{-j 2 \pi f \tau} d \tau & \\
& =\lim _{T \rightarrow \infty} \frac{1}{T} X_{T}\left(f+\frac{\alpha}{2}\right) X_{T}^{*}\left(f-\frac{\alpha}{2}\right)
\end{aligned}
$$

Where $\quad X_{T}(f)=\int_{-\frac{T}{2}}^{\frac{T}{2}} x(u) e^{-j 2 \pi f u} d u$

From the spectral correlation density plot we can extract the parameters easily.

\subsection{FFT Accumulation Method}

The time smoothing FFT accumulation method is one of the most used techniques which involves a large number of small computations. The Fig.2 shows the block diagram of the FAM method.

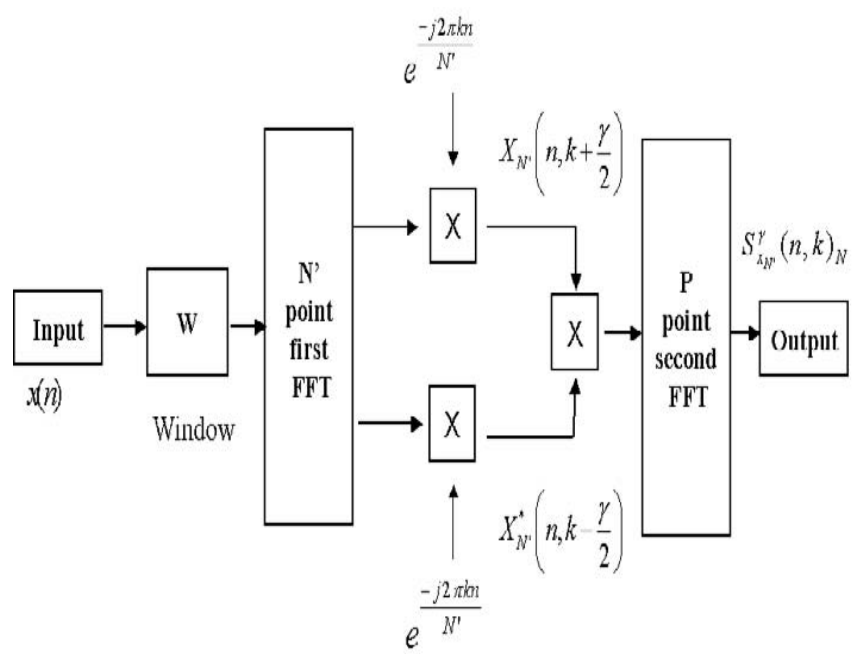

Fig.2.FFT Accumulation Method

The algorithm consists of three stages: computation of the complex demodulates (divided into data tapering, sliding N' point Fourier transform, and baseband frequency translation sections), computation of the product sequences and smoothing of the product sequences. The parameter $\mathrm{N}$ represents the total number of discrete samples within the observation time, and N' represents the number of points within the discrete short-time (sliding) FFT. In the FAM algorithm, spectral components of a sequence, $\mathrm{x}(\mathrm{n})$, are computed using (4). Two components are multiplied (3) to provide a sample of a cyclic spectrum estimate representing the finite channel pair region on the bi-frequency plane. There are N2 channel pair regions in the bi-frequency plane. A sequence of samples for any particular area may be obtained by multiplying the same two elements of a series of consecutive short-time sliding FFTs along the entire length of the input sequence. After the channelization performed by an N'-point FFT sliding over the data with an overlap of L samples, the outputs of the FFTs are shifted in frequency in order to obtain the complex demodulate sequences. Instead of computing the average of the product of sequences 
between the complex demodulates, they are Fouriertransformed with a P-point (second) FFT. The computational efficiency of the algorithm is improved by a factor of L, since only N/L samples are processed for each point estimate. With fs the sampling frequency, the cycle frequency resolution of the decimated algorithm is defined as $\gamma \mathrm{res}=\mathrm{fs} / \mathrm{N}$ (compare to $\Delta \alpha=1 / \Delta \mathrm{t}$ ), the frequency resolution is kres $=\mathrm{fs} / \mathrm{N}^{\prime}$ (compare to $\Delta \mathrm{f}=1 / \mathrm{TW}$ ), and the Grenander's Uncertainty Condition is $M=N / N^{\prime}>>1$.

\subsection{DFSM}

Direct frequency-smoothing algorithms first compute the spectral components of the data and then execute spectralcorrelation operations directly on the spectral components. The direct frequency-smoothing method is computationally superior to indirect algorithms that use related quantities such as the Wigner-Ville Distribution, but DFSM is usually less efficient than a time-smoothing approach.

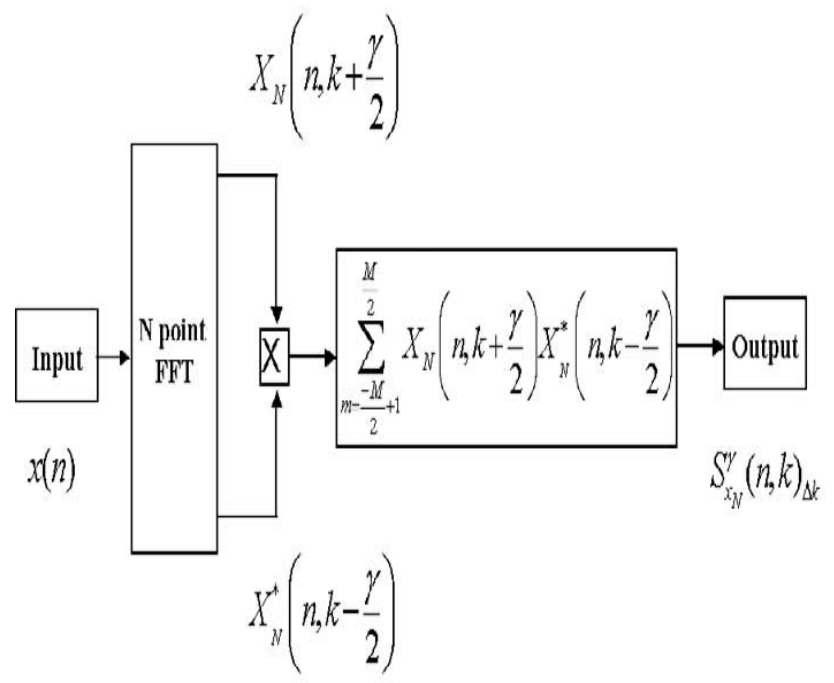

Fig.3.Direct Frequency Smoothing Method

The basis for the DFSM is the discrete time frequencysmoothed cyclic periodogram represented by equation (6)

$$
\mathrm{S}_{\mathrm{X}_{\mathrm{N}}}^{\gamma}(\mathrm{n}, \mathrm{k})=\frac{1}{\mathrm{~N}} \sum_{\mathrm{n}=0}^{\mathrm{N}-1} \mathrm{X}_{\mathrm{N}}\left(\mathrm{n}, \mathrm{k}+\frac{\gamma}{2}\right) \mathrm{X}_{\mathrm{N}}^{*}\left(\mathrm{n}, \mathrm{k}-\frac{\gamma}{2}\right)
$$

Where

$$
X_{N}(n, k)=\sum_{n=0}^{N-1} w(n) x(n) e^{-j 2 \pi k n / N}
$$

is the discrete Fourier transform of $\mathrm{x}(\mathrm{n}), \mathrm{w}(\mathrm{n})$ is the rectangular window of length $\mathrm{N}$ that is the total number of points of the FFT related to the total observation time, $\Delta \mathrm{t}, \gamma$ is the cycle frequency discrete equivalent, the frequencysmoothed ranges over the interval $|\mathrm{m}| \leq \mathrm{M} / 2$, and $\Delta \mathrm{k} \approx \mathrm{M}$. $\mathrm{fs} / \mathrm{N}$ is the frequency resolution discrete equivalent.

\section{RESULTS AND DISCUSSIONS}

The Polytime codes best approximates the underlying stepped-RF waveform when compared polyphase codes in which only phase will changes and time spent at each phase state is constant. But in Polytime codes for a fixed number of phase states the time spent on each phase state will changes. If the number of phase states are increased then the time spent on each phase state decreases resulting in a signal which is very difficult to analyze. The minimum bit duration plays an important role which related to bandwidth as $\mathrm{BW}=1 / \mathrm{t}_{\mathrm{b}}$. The minimum bit duration depends on number of sub pulses $(\mathrm{k})$, duration of each sub pulse $(\tau)$ and number of phase states (n) as follows

$$
\mathrm{t}_{\mathrm{b}}=\frac{\tau}{(\mathrm{k}-1) \mathrm{n}}
$$

The techniques FAM and DFSM will give results which agree well with the actual values. The similarities between the DFSM results and the FAM results go until a certain level; in the zoomed plots we see that the channel pair regions are a little different in shape and size, although they occur in the same values for frequency and cycle frequency. This may be the result of the different windows applied in each method (Hamming window for FAM and Rectangular window for DFSM).

The number of computations required for FAM are

$$
\mathrm{N}_{\text {comp }}=2 * \mathrm{P}^{*} \mathrm{~N}^{\prime}+\mathrm{P}^{*} \mathrm{~N}^{\prime} * \underset{\log 2 \mathrm{~N}^{\prime}+2 * \mathrm{P}^{*} \mathrm{~N}^{\prime}+\mathrm{P}^{*}\left(\mathrm{~N}^{\prime}\right) 2+\left(\mathrm{N}^{\prime}\right) 2(\mathrm{P} / 2)}{\log 2 \mathrm{P}}
$$

Where $\mathrm{P}=\mathrm{N} / \mathrm{L}$ and $\mathrm{L}=\mathrm{N}^{\prime} / 4$

The number of computations required for DFSM are

$$
\mathrm{N}_{\text {comp }}=\mathrm{N} 2+2 * \mathrm{~N} * \log 2 \mathrm{~N} \text {. }
$$

So the computing time is also noticeably larger, two or three times more, for the DFSM routine in comparison to the FAM routine. The FAM implementation is recommended for long signals with a large number of samples. We can extract parameters from the signal even at an extreme signal to noise ratio conditions $(-6 \mathrm{~dB})$. The number of phase states and number of segments are difficult to find. If the overall code duration increases the resolution in extracted parameters will also increases.

\subsection{Cyclostationary Analysis on Polytime signal T1(n)}

Analysis of polytime code signal include signal, with and without the addition of White Gaussian Noise, and extraction of their main characteristics. The results of these signals are shown below. The contour plots show frequencycycle frequency domain of the results. 
First, the carrier frequency fc can be clearly found by the location of the modulation pattern, The T1 modulation shows up in the four quadrants centered on cycle frequency $(\gamma), \quad \gamma=2 \mathrm{f}_{\mathrm{c}}=2 \mathrm{GHz}$ as shown in fig.4.2. So, carrier frequency is measured as $1 \mathrm{GHz}$. Secondly, in fig. 4.2, bandwidth can be calculated as width from center of modulation pattern to end of pattern on cycle frequency axis, hence measured as $1750 \mathrm{MHz}$. Since

$$
B=\frac{1}{t_{b}}
$$

For polytime codes $\mathrm{Rc}=1 / \mathrm{T}$, The code rate $(\mathrm{Rc})$ is distance between any two adjacent spots on cycle frequency axis and is measured as $62 \mathrm{MHz}$ in Figure 4.3. So the total time duration of the signal will be calculated as $\mathrm{T}=1 / \mathrm{Rc}=16$ nSec.

\subsubsection{PT1_1000000_7000000_2_4_S}

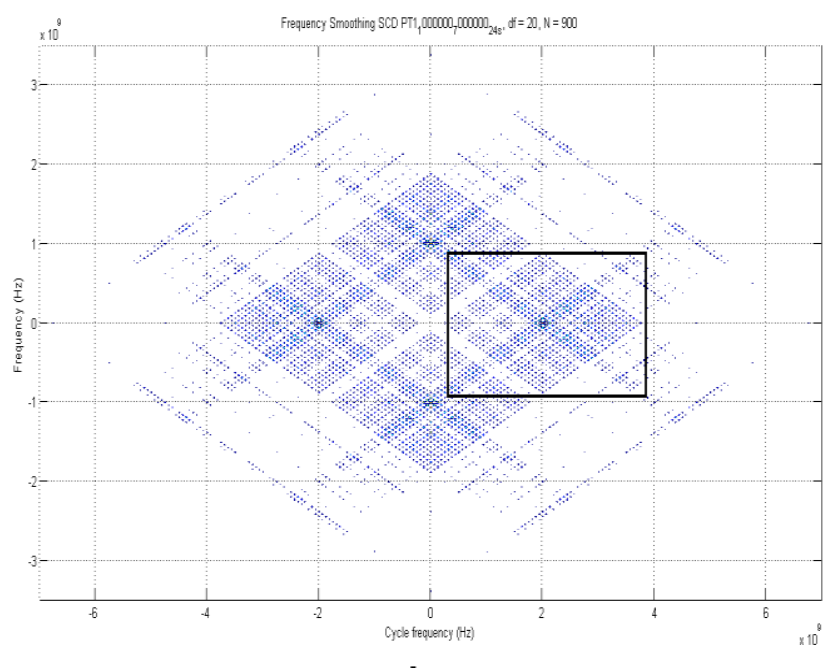

Fig 4.1: $\mathrm{SCD}$ patterns for the $\mathrm{T} 1$ code with $\mathrm{n}=2, \mathrm{fc}=1$ $\mathrm{GHz}$, and $\mathrm{T}=16 \mathrm{nSec}$

Fig.4.2 showing measurement of bandwidth which is the distance between center of modulation pattern to end of pattern on cycle frequency axis.

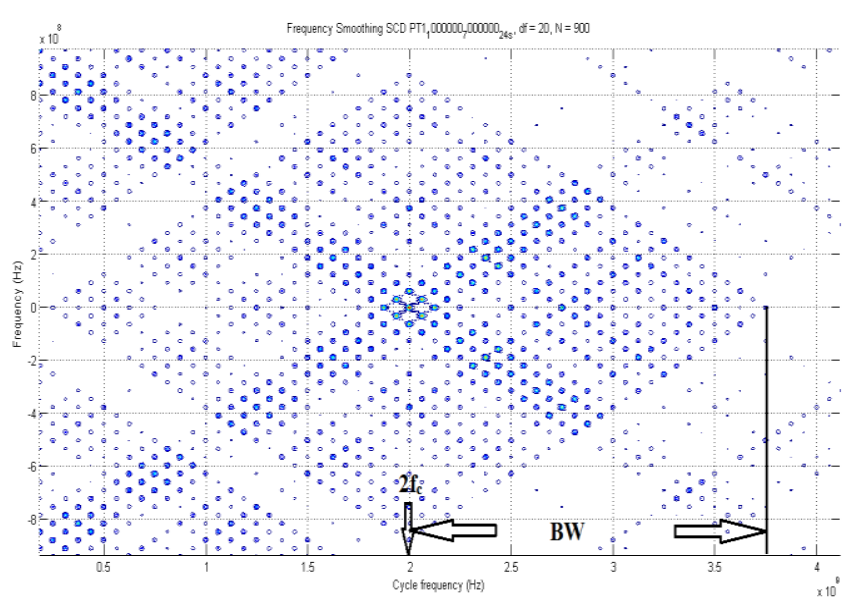

Fig 4.2: A close up of selected pattern and illustrating bandwidth measurement
Fig.4.3 showing measurement of Code-Rate which is distance between any two adjacent spots on cycle frequency axis.

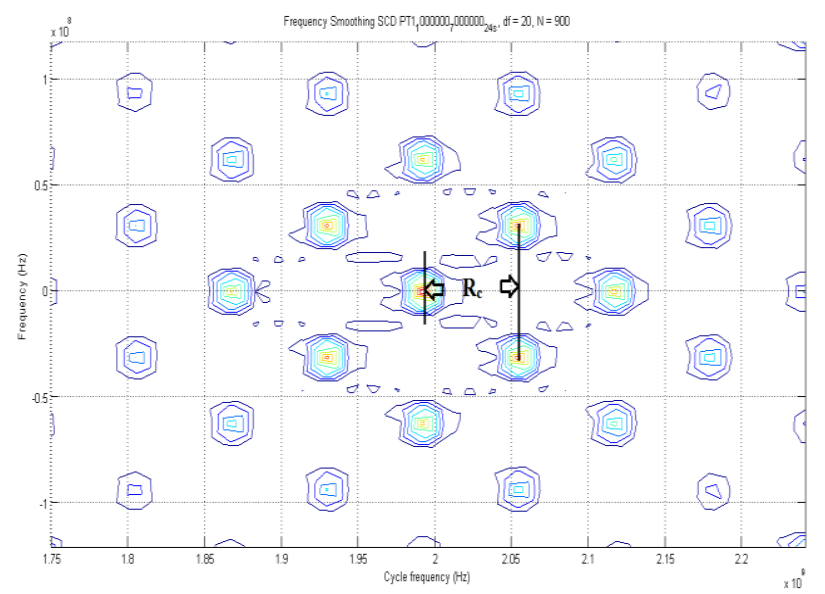

Fig 4.3: illustrating Code Rate measurement

Table-1: Comparison between measured and original Characteristics for signal PT1_1000000_7000000_2_4_s

\begin{tabular}{|l|l|l|}
\hline $\begin{array}{l}\text { FEATURE EXTRACTION } \\
\text { OT1_1000000_7000000_2_s }\end{array}$ \\
\hline $\begin{array}{l}\text { CHARACTERSTI } \\
\text { C }\end{array}$ & ORIGINAL & $\begin{array}{l}\text { MEASU } \\
\text { RED }\end{array}$ \\
\hline $\begin{array}{l}\text { Carrier Frequency } \\
\left(\mathbf{f}_{\mathbf{c}}\right)\end{array}$ & $1000 \mathrm{MHz}$ & $1000 \mathrm{MHz}$ \\
\hline Bandwidth $(\mathbf{B})$ & $1750 \mathrm{MHz}$ & $1750 \mathrm{MHz}$ \\
\hline Code Rate $\left(\mathbf{R}_{\mathbf{c}}\right)$ & $62.5 \mathrm{MHz}$ & $62.5 \mathrm{MHz}$ \\
\hline Code Period $(\mathbf{T})$ & $16 \mathrm{nSec}$ & $16 \mathrm{nSec}$ \\
\hline
\end{tabular}

The above results were analyzed under noise less condition in which last letter for the signal indiacaters different noise conditions. The analysis is carried out for s-signal only condition,0-0dB SNR, and -6dB SNR.

\subsubsection{PT1_1000000_7000000_2_4_0}

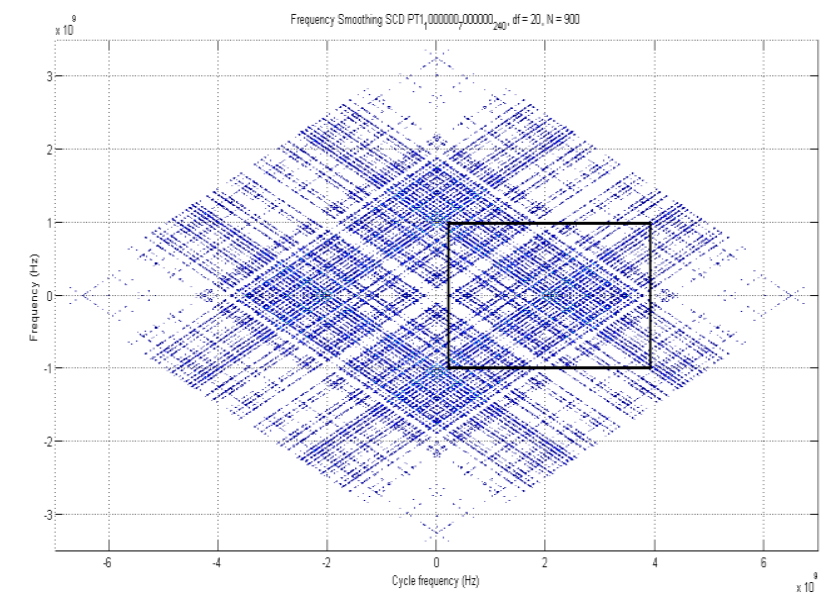

Fig 4.4: $\mathrm{SCD}$ patterns for the $\mathrm{T} 1$ code with $\mathrm{SNR}=0 \mathrm{~dB}$, $\mathrm{fc}$ $=1 \mathrm{GHz}$, and $\mathrm{T}=16 \mathrm{nSec}$

Fig4.5 showing measurement of bandwidth which is the distance between center of modulation pattern to end of pattern on cycle frequency axis 


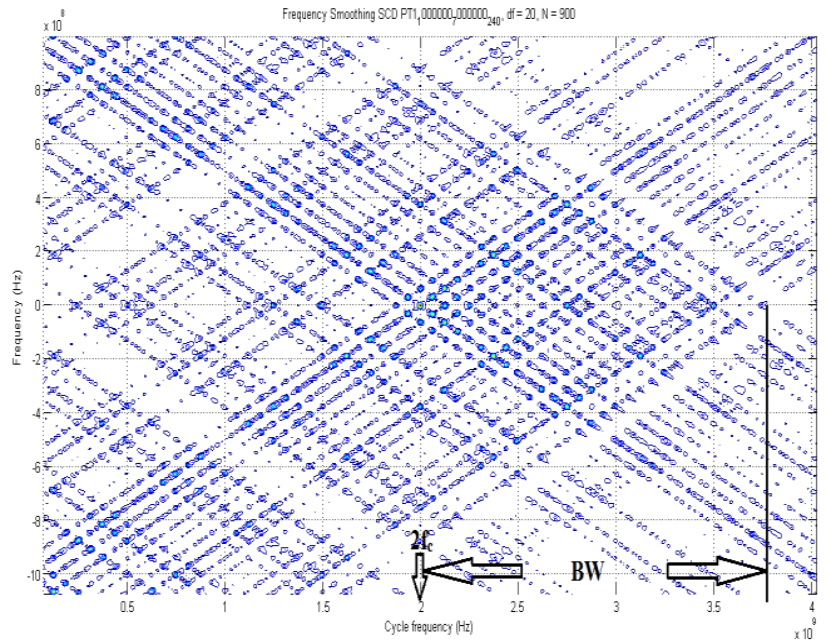

Fig 4.5: a close-up of selected pattern and illustrating Bandwidth measurement

Fig4.6 showing measurement of Code-Rate which is distance between any two adjacent spots on cycle frequency axis.

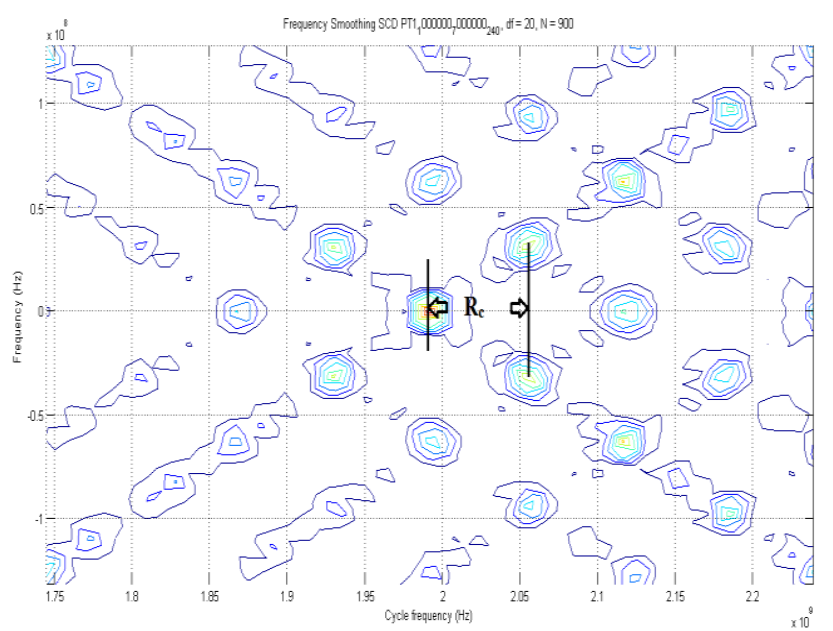

Fig 4.6: illustrating Code Rate measurement

Table-2: Comparison between measured and original Characteristics for signal PT1_1000000_7000000_2_4_0

\begin{tabular}{|l|l|l|}
\hline $\begin{array}{l}\text { FEATURE EXTRACTION } \\
\text { PT1_1000000_7000000_4_0 }\end{array}$ \\
\hline CHARACTERSTIC & ORIGINAL & MEASURED \\
\hline $\begin{array}{l}\text { Carrier Frequency } \\
\text { (f) }\end{array}$ & $1000 \mathrm{MHz}$ & $1000 \mathrm{MHz}$ \\
\hline Bandwidth $(\mathbf{B})$ & $1750 \mathrm{MHz}$ & $1750 \mathrm{MHz}$ \\
\hline Code Rate $\left(\mathbf{R}_{\mathbf{c}}\right)$ & $62.5 \mathrm{MHz}$ & $62 \mathrm{MHz}$ \\
\hline Code Period $(\mathbf{T})$ & $16 \mathrm{nSec}$ & $16.12 \mathrm{nSec}$ \\
\hline
\end{tabular}

\subsubsection{PT1_1000000_7000000_2_4_-6}

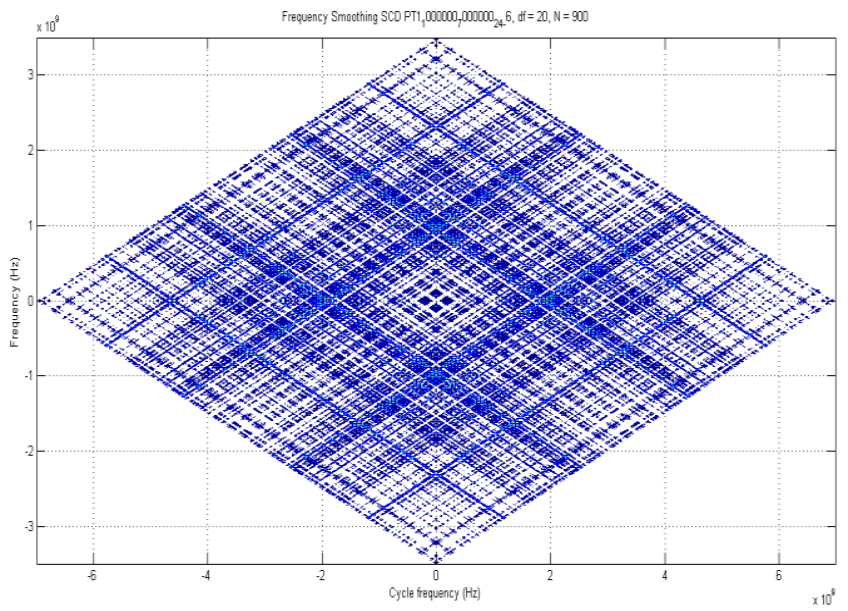

Fig 4.7: $\mathrm{SCD}$ patterns for the $\mathrm{T} 1$ code with $\mathrm{fc}=1 \mathrm{GHz}$, and $\mathrm{T}=16 \mathrm{nSec}$

Table-3: Comparison between measured and original Characteristics for signal PT1_1000000_7000000_2_4_-6

\begin{tabular}{|l|l|l|}
\hline FEATURE EXTRACTION & FOR \\
PT1_1000000_7000000_2_4_6 & $\begin{array}{l}\text { MEAS } \\
\text { URED }\end{array}$ \\
\hline CHARACTERSTIC & ORIGINAL & - \\
\hline Carrier Frequency $\left(\mathbf{f}_{\mathbf{c}}\right)$ & $1000 \mathrm{MHz}$ & - \\
\hline Bandwidth $(\mathbf{B})$ & $1750 \mathrm{MHz}$ & - \\
\hline Code Rate $\left(\mathbf{R}_{\mathbf{c}}\right)$ & $62.5 \mathrm{MHz}$ & - \\
\hline Code Period $(\mathbf{T})$ & $16 \mathrm{nSec}$ & - \\
\hline
\end{tabular}

Table-4: Comaparison between generated and extracted paprameters with sampling frequency $\mathrm{fs}=3 \mathrm{GHz}$ for various SNR conditions.

\begin{tabular}{|c|c|c|c|c|c|c|c|c|}
\hline \multirow{3}{*}{ SNR } & \multicolumn{8}{|c|}{ High frequency analysis of $\mathrm{T} 1(2)$ for $F_{s}=3 \mathrm{GHz}$} \\
\hline & \multicolumn{2}{|c|}{$\mathbf{F}_{\mathrm{c}}(\mathrm{MHz})$} & \multicolumn{2}{|c|}{$\begin{array}{l}\text { BW } \\
\text { (MHz) }\end{array}$} & \multicolumn{2}{|c|}{$\mathbf{R}_{\mathrm{c}}(\mathrm{MHz})$} & \multicolumn{2}{|c|}{$\mathbf{T}(\mathbf{n ~ S e c})$} \\
\hline & IN & $\begin{array}{l}\mathrm{OU} \\
\mathrm{T}\end{array}$ & IN & $\begin{array}{l}\mathrm{OU} \\
\mathrm{T}\end{array}$ & IN & $\begin{array}{l}\mathrm{OU} \\
\mathrm{T}\end{array}$ & $\begin{array}{l}\mathrm{I} \\
\mathrm{N}\end{array}$ & $\begin{array}{l}\mathrm{OU} \\
\mathrm{T}\end{array}$ \\
\hline $\begin{array}{l}\text { Sign } \\
\text { al } \\
\text { only }\end{array}$ & $\begin{array}{l}100 \\
0\end{array}$ & $\begin{array}{l}100 \\
0\end{array}$ & $\begin{array}{l}175 \\
0\end{array}$ & $\begin{array}{l}130 \\
0\end{array}$ & $\begin{array}{l}62 . \\
5\end{array}$ & 62 & $\begin{array}{l}1 \\
6\end{array}$ & $\begin{array}{l}16.1 \\
2\end{array}$ \\
\hline $0 \mathrm{~dB}$ & $\begin{array}{l}100 \\
0\end{array}$ & $\begin{array}{l}105 \\
0\end{array}$ & $\begin{array}{l}175 \\
0\end{array}$ & $\begin{array}{l}110 \\
0\end{array}$ & $\begin{array}{l}62 . \\
5\end{array}$ & 62 & $\begin{array}{l}1 \\
6\end{array}$ & $\begin{array}{l}16.1 \\
2\end{array}$ \\
\hline$-2 \mathrm{~dB}$ & $\begin{array}{l}100 \\
0\end{array}$ & 950 & $\begin{array}{l}175 \\
0\end{array}$ & $\begin{array}{l}105 \\
0\end{array}$ & $\begin{array}{l}62 . \\
5\end{array}$ & 65 & $\begin{array}{l}1 \\
6\end{array}$ & $\begin{array}{l}15.3 \\
8\end{array}$ \\
\hline$-4 \mathrm{~dB}$ & $\begin{array}{l}100 \\
0\end{array}$ & $\begin{array}{l}100 \\
0\end{array}$ & $\begin{array}{l}175 \\
0\end{array}$ & 970 & $\begin{array}{l}62 . \\
5\end{array}$ & - & $\begin{array}{l}1 \\
6\end{array}$ & - \\
\hline$-6 \mathrm{~dB}$ & $\begin{array}{l}100 \\
0\end{array}$ & $\begin{array}{l}110 \\
0\end{array}$ & $\begin{array}{l}175 \\
0\end{array}$ & 980 & $\begin{array}{l}62 . \\
5\end{array}$ & - & $\begin{array}{l}1 \\
6\end{array}$ & - \\
\hline
\end{tabular}


Table-5: Comaparison between generated and extracted paprameters with sampling frequency $\mathrm{fs}=5 \mathrm{GHz}$ for various SNR conditions.

\begin{tabular}{|c|c|c|c|c|c|c|c|c|}
\hline \multirow{3}{*}{ SNR } & \multicolumn{8}{|c|}{ High frequency analysis of T1(2) for $F_{s}=5 \mathrm{GHz}$} \\
\hline & \multicolumn{2}{|c|}{$\mathbf{F}_{\mathrm{c}}(\mathbf{M H z})$} & \multicolumn{2}{|c|}{$\begin{array}{l}\text { BW } \\
\text { (MHz) }\end{array}$} & \multicolumn{2}{|c|}{$\mathbf{R}_{\mathrm{c}}(\mathbf{M H z})$} & \multicolumn{2}{|c|}{$\mathbf{T}(\mathrm{n} \mathrm{Sec})$} \\
\hline & IN & $\begin{array}{l}\mathrm{OU} \\
\mathrm{T}\end{array}$ & IN & $\begin{array}{l}\mathrm{OU} \\
\mathrm{T} \\
\end{array}$ & IN & $\begin{array}{l}\mathrm{OU} \\
\mathrm{T}\end{array}$ & $\begin{array}{l}\mathrm{I} \\
\mathrm{N}\end{array}$ & $\begin{array}{l}\mathrm{OU} \\
\mathrm{T}\end{array}$ \\
\hline $\begin{array}{l}\text { Sign } \\
\text { al } \\
\text { only }\end{array}$ & $\begin{array}{l}100 \\
0\end{array}$ & $\begin{array}{l}100 \\
0\end{array}$ & $\begin{array}{l}175 \\
0\end{array}$ & $\begin{array}{l}175 \\
0\end{array}$ & $\begin{array}{l}62 . \\
5\end{array}$ & 62.5 & $\begin{array}{l}1 \\
6\end{array}$ & 16 \\
\hline $0 \mathrm{~dB}$ & $\begin{array}{l}100 \\
0\end{array}$ & 900 & $\begin{array}{l}175 \\
0\end{array}$ & $\begin{array}{l}170 \\
0 \\
\end{array}$ & $\begin{array}{l}62 . \\
5 \\
\end{array}$ & 62 & $\begin{array}{l}1 \\
6\end{array}$ & $\begin{array}{l}16.1 \\
2\end{array}$ \\
\hline$-2 \mathrm{~dB}$ & $\begin{array}{l}100 \\
0 \\
\end{array}$ & 900 & $\begin{array}{l}175 \\
0 \\
\end{array}$ & $\begin{array}{l}150 \\
0 \\
\end{array}$ & $\begin{array}{l}62 . \\
5 \\
\end{array}$ & 62 & $\begin{array}{l}1 \\
6\end{array}$ & $\begin{array}{l}16.1 \\
2\end{array}$ \\
\hline$-4 d B$ & $\begin{array}{l}100 \\
0\end{array}$ & $\begin{array}{l}105 \\
0\end{array}$ & $\begin{array}{l}175 \\
0\end{array}$ & 900 & $\begin{array}{l}62 . \\
5 \\
\end{array}$ & 62 & $\begin{array}{l}1 \\
6\end{array}$ & $\begin{array}{l}16.1 \\
2\end{array}$ \\
\hline$-6 \mathrm{~dB}$ & $\begin{array}{l}100 \\
0\end{array}$ & 950 & $\begin{array}{l}175 \\
0\end{array}$ & $\begin{array}{l}105 \\
0\end{array}$ & $\begin{array}{l}62 . \\
5\end{array}$ & 65 & $\begin{array}{l}1 \\
6\end{array}$ & $\begin{array}{l}15.3 \\
8\end{array}$ \\
\hline
\end{tabular}

Table-6: Comaparison between generated and extracted paprameters with sampling frequency $\mathrm{fs}=7 \mathrm{GHz}$ for various SNR conditions.

\begin{tabular}{|c|c|c|c|c|c|c|c|c|}
\hline \multirow{3}{*}{ SNR } & \multicolumn{8}{|c|}{ High frequency analysis of $\mathrm{T} 1(2)$ for $F_{s}=7 \mathrm{GHz}$} \\
\hline & \multicolumn{2}{|c|}{$\mathrm{F}_{\mathrm{c}}(\mathrm{MHz})$} & \multicolumn{2}{|c|}{$\begin{array}{l}\text { BW } \\
\text { (MHz) }\end{array}$} & \multicolumn{2}{|c|}{$\mathbf{R}_{\mathrm{c}}(\mathrm{MHz})$} & \multicolumn{2}{|c|}{$\mathbf{T}(\mathrm{n} \mathrm{Sec})$} \\
\hline & IN & $\begin{array}{l}\mathrm{OU} \\
\mathrm{T}\end{array}$ & IN & $\begin{array}{l}\mathrm{OU} \\
\mathrm{T} \\
\end{array}$ & IN & $\begin{array}{l}\text { OU } \\
\mathrm{T}\end{array}$ & $\begin{array}{l}\mathrm{I} \\
\mathrm{N}\end{array}$ & $\begin{array}{l}\mathrm{OU} \\
\mathrm{T}\end{array}$ \\
\hline $\begin{array}{l}\text { Sign } \\
\text { al } \\
\text { only }\end{array}$ & $\begin{array}{l}100 \\
0\end{array}$ & $\begin{array}{l}100 \\
0\end{array}$ & $\begin{array}{l}175 \\
0\end{array}$ & $\begin{array}{l}175 \\
0\end{array}$ & $\begin{array}{l}62 . \\
5\end{array}$ & 62.5 & $\begin{array}{l}1 \\
6\end{array}$ & 16 \\
\hline $0 \mathrm{~dB}$ & $\begin{array}{l}100 \\
0\end{array}$ & $\begin{array}{l}100 \\
0\end{array}$ & $\begin{array}{l}175 \\
0\end{array}$ & $\begin{array}{l}175 \\
0\end{array}$ & $\begin{array}{l}62 . \\
5\end{array}$ & 62 & $\begin{array}{l}1 \\
6 \\
\end{array}$ & $\begin{array}{l}16.1 \\
2\end{array}$ \\
\hline$-2 \mathrm{~dB}$ & $\begin{array}{l}100 \\
0\end{array}$ & $\begin{array}{l}100 \\
0 \\
\end{array}$ & $\begin{array}{l}175 \\
0\end{array}$ & $\begin{array}{l}175 \\
0 \\
\end{array}$ & $\begin{array}{l}62 . \\
5\end{array}$ & 62 & $\begin{array}{l}1 \\
6\end{array}$ & $\begin{array}{l}16.1 \\
2\end{array}$ \\
\hline$-4 \mathrm{~dB}$ & $\begin{array}{l}100 \\
0\end{array}$ & $\begin{array}{l}100 \\
0\end{array}$ & $\begin{array}{l}175 \\
0 \\
\end{array}$ & $\begin{array}{l}150 \\
0 \\
\end{array}$ & $\begin{array}{l}62 . \\
5\end{array}$ & 62 & $\begin{array}{l}1 \\
6\end{array}$ & $\begin{array}{l}16.1 \\
2\end{array}$ \\
\hline$-6 \mathrm{~dB}$ & $\begin{array}{l}100 \\
0\end{array}$ & - & $\begin{array}{l}175 \\
0\end{array}$ & - & $\begin{array}{l}62 . \\
5\end{array}$ & - & $\begin{array}{l}1 \\
6\end{array}$ & - \\
\hline
\end{tabular}

\section{CONCLUSION}

The goal of this work is to implement two cyclostationary processing techniques (Time and Frequency-Smoothing algorithms). The FAM and DFSM methods will give results which are agree well with the actual values. The DFSM took more time to execute than FAM. In DFSM as we use rectangular window the output plot does not have the resolution to calculate the output where as in FAM we use hamming window and the number of values can be truncated and the FFT is used to reduce computations. So for long signals and high data values and for fast computation FAM method is prefferable than DFSM. Extraction of parameters of LPI Radar signal is easier at various sampling frequencies till sampling frequency is considered three times of carrier. It is possible to extract all parameters till SNR $=-6 \mathrm{~dB}$, extraction of Code-Rate is difficult under low SNR $=-6 \mathrm{~dB}$ but it is possible to extract carrier frequency and bandwidth.

\section{REFERENCES}

[1] Merril I.Skolnik;Introduction To Radar Systems, $3^{\text {rd }}$ Edition McGraw-Hill Education, 2003

[2] Ramya Vellanki1, K.Satish Babu2"Modeling and Analysis of LPI Radar Signal", IOSR Journal of Electronics and Communication Engineering (IOSRJECE) e-ISSN: 2278-2834,p- ISSN: 22788735. Volume 8, Issue 2 (Nov. - Dec. 2013), PP 1926.

[3] Seyed Mohammad Hosseini, Reza Mohseni, "Interception FMCW radar using Wigner-Ville Distribution(WVD)," Majlesi Journal of Telecommunication Devices Vol. 2, No. 4, December 2013.

[4] Shixian Wang, Hengzhu Liu, Botao Zhang, Lunguo Xie," Parallel Computation based Spectrum Sensing Implementation for Cognitive Radio", ISSN 1392 1215 Electronics and electrical engineering 2012. No. 2(118)

[5] William A. Gardner, "The spectral correlation theory of cyclostationary time series", University of California at Davis, Davis, CA95616, USA

[6] Fielding,J.E. Radian Int., Austin, TX," Polytime coding as a means of pulse compression", IEEE transaction on Aerospace and Electronic systems VOL 35, NO.2, April 1999.

[7] Tom, C. -“Cyclostationary Spectral Analysis of Typical SATCOM Signals Using the FFT Accumulation Method", - DREO Report 1280, DECEMBER 1995.

[8] Pace, P.E. - "Detection and classification of LPI Radars", 2nd edition.

[9] Randy S. Roberts, Herschel H. Loomis, Jr. on "Computational balance in real time cyclic spectral analysis. 


\section{BIOGRAPHIES}

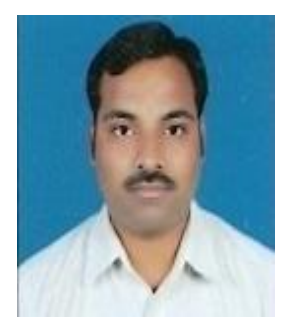

Mr. Metuku Shyamsunder has obtained his graduation from IETE and Masters in microwave from NIT Bhopal. He has 11 years of teaching and research experience. His research interests are microwave, signal processing, and embedded systems. He is currently working as assistant professor in Department of ECE, UCE (A), OU. He is also a research scholar at ECE department at University College of engineering, Osmania University.

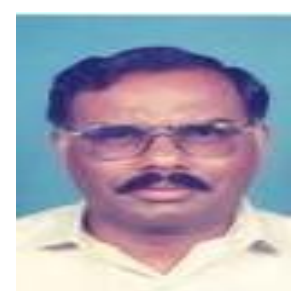

Dr. Kakarla Subba Rao did his Bachelor's degree in Electrical Engineering from Government College, Anantapur and Master's and $\mathrm{Ph}$. D degrees from Osmaina University, Hyderabad. Dr. Subba Rao is currently working as Professor, Dept of ECE, CBIT, Hyderabad. He has published more than 120 research papers in International and National Journals/Conferences. He has conducted several short term courses in the Dept. of ECE, OU and various organizations like DRDO, ECIL. Under SONET program, a series of lectures on 'Digital Signal Processing' subject as per the JNTU syllabus were recorded. He has successfully completed four major research projects sponsored by AICTE, DRDO and Analog Devices, Bangalore in the areas of Radar and multimedia signal processing. $\mathrm{He}$ is an expert member for NBA and also member of Board of studies in ECE for JNTUH and Srinidhi Institute of Technology. His areas of research interests include Signal Processing, Signal Design and Modeling of Biological systems. 